\title{
Seasonal ecology and life-history strategy of the high-latitude predatory zooplankter Parasagitta elegans
}

\author{
Jordan J. Grigor ${ }^{1,2, *}$, Janne E. Søreide1, Øystein Varpe ${ }^{1,3}$ \\ ${ }^{1}$ The University Centre in Svalbard, 9171 Longyearbyen, Norway \\ ${ }^{2}$ Takuvik Joint International Laboratory, Université Laval (Canada) - CNRS (France), \\ Département de biologie and Québec-Océan, Université Laval, Québec, Québec G1V 0A6, Canada \\ ${ }^{3}$ Akvaplan-niva, Fram Centre, 9296 Tromsø, Norway
}

\begin{abstract}
Organisms residing in seasonal environments schedule their activities to annual cycles in prey availability and predation risk. These cycles may be particularly pronounced in pelagic ecosystems of the high-Arctic, where the seasonality in irradiance, and thus primary production, is strong. Here we report on the seasonal ecology and life strategy of a predatory planktivore in a high-Arctic fjord (Billefjorden, Svalbard $\sim 78^{\circ} \mathrm{N}$ ). We studied the chaetognath Parasagitta elegans (var. arctica), an abundant zooplankter of high-latitude seas, focusing on its age structure, seasonal vertical distribution, growth and timing of reproduction. The body-length data (range: 2 to $44 \mathrm{~mm}$ ) revealed the presence of 3 size cohorts (Cohorts 0,1 and 2), suggesting a 3 yr life span. Spring and early summer (May/June) was the main spawning season, as revealed by inspection of gonads and the presence of well-developed seminal receptacles prior to high numbers of newborns. Both Cohorts 1 and 2 reproduced, with male gonads maturing first in this hermaphrodite. Growth rates for all cohorts were highest in spring and early summer, and at this time of the year, the youngest year class (Cohort 0) was distributed near the surface where their feeding opportunities may peak. In winter, however, all cohorts were in deeper waters, suggesting seasonal migrations, possibly to follow the distributions of overwintering copepods. Scheduling of growth, maturation and reproduction in Arctic zooplankton populations is important baseline information for predictions of zooplankton responses to environmental change, particularly those associated with timing and phenology, pinpointing the need for more high-resolution studies on zooplankton annual routines.
\end{abstract}

KEY WORDS: Annual routines · Arctic $\cdot$ Arrow worms $\cdot$ Seasonal environments $\cdot$ Zooplankton

\section{INTRODUCTION}

The life histories of Arctic animals have evolved in response to a highly seasonal environment. In the marine pelagic, near-surface biomass shows a strong seasonal signal, caused by both the pulse of primary production (Ji et al. 2013) and the presence of seasonally migrating grazers for corresponding parts of the year (Varpe 2012). High-latitude zooplankton show many adaptations to a seasonal food source, some of which are associated with body lipid content,

*Corresponding author: jordangrigor@gmail.com diapause and timing and the extent of growth and reproduction (e.g. Falk-Petersen et al. 2009, Varpe 2012). Diel and seasonal vertical migrations (DVM and SVM), observed in various zooplankton species, are also adaptations to the interactions between temporal and spatial distribution of food and predators that occur over varying timescales (Haney 1988). In sum, organisms in seasonal environments have typically evolved schedules of activities over the annual cycle, referred to as annual routines (McNamara \& Houston 2008, Varpe 2012).

(C) The authors 2014. Open Access under Creative Commons by Attribution Licence. Use, distribution and reproduction are unrestricted. Authors and original publication must be credited. 
In the Arctic, the bulk of seasonal studies has focused on the link between primary producers and their grazers (e.g. Søreide et al. 2010, Daase et al. 2013), but planktonic predators (chaetognaths, some copepods, ctenophores, decapods, amphipods etc.) may display similarly marked adaptations to seasonality (e.g. Choe et al. 2003, Dale et al. 2006). In this study we have examined the seasonal ecology and life history of the chaetognath Parasagitta elegans var. arctica (genus name formerly Sagitta).

Chaetognaths form a phylum of gelatinous zooplankton predators, comprising 5 to $15 \%$ of global zooplankton biomass (Longhurst 1985) and approximately 200 species worldwide (Ghirardelli 1997). Chaetognaths are hermaphrodites capable of both cross- and self-fertilisation (Alvarino 1992). Three major species can be found in Arctic waters: Parasagitta elegans, Eukrohnia hamata and Pseudosagitta maxima, and they contribute substantially to Arctic zooplankton biomass (Søreide et al. 2003, Hopcroft et al. 2005). However, their roles in energy and elemental flux are not well described, particularly not during the polar night (e.g. Welch et al. 1992). P. elegans often dominates chaetognath communities in Arctic shelf seas (Dunbar 1962, Welch et al. 1996), whereas the other 2 species may be more common at mesoto bathypelagic depths offshore (Kosobokova et al. 2011). P. elegans is a heterogeneous feeder, but calanoid and cyclopoid copepods are its major prey (see review by Terazaki 2004), and it can consume relatively high portions of the daily secondary production (Samemoto 1987). P. elegans is also an important prey item for others, including chaetognaths, amphipods, jellyfish, fish and seabirds (Feigenbaum \& Maris 1984 and references therein).

The life cycle of Parasagitta elegans varies considerably throughout its distribution range, possibly due to variability in environmental factors such as temperature and food availability (Terazaki 2004). For instance, specimens from the Canadian Arctic may have longer lifespans than those residing at lower latitudes (Dunbar 1962, Terazaki 2004). The number of generations produced in a year also varies considerably, from 0.5 generations at the sub-Arctic setting of Hudson Bay, Canada (65 N; Dunbar 1962), to possibly 5 to 6 in Plymouth, UK $\left(50^{\circ} \mathrm{N}\right.$; Russell 1932). Vertical migration behaviour has been less explored in Arctic chaetognaths. In the Arctic, migrations of herbivorous zooplankton have received most attention (Falk-Petersen et al. 2009 and references therein), but several studies have reported both SVM and DVM in lower-latitude populations of P. elegans (Terazaki 2004 and references therein).
In order to study the seasonal ecology and lifehistory strategy of Parasagitta elegans, we gathered monthly data in a high-Arctic sill fjord with restricted water mass exchange and seasonal sea ice cover. We investigated the timing of growth, maturation and reproduction as well as age structure and vertical distributions from July 2008 to August 2009. We related our findings to the seasonality of the environment.

\section{MATERIALS AND METHODS}

\section{Study site}

The zooplankton community in Adolfbukta, Billefjorden, on the west coast of Spitsbergen $\left(78^{\circ} 39.72^{\prime} \mathrm{N}\right.$, $\left.16^{\circ} 44.34^{\prime} \mathrm{E}\right)$ was sampled monthly from July 2008 to August 2009. Billefjorden is a threshold fjord with 2 sills at its mouth, which in previous studies have been shown to severely restrict exchange of water masses, particularly the entry of Atlantic water (Nilsen et al. 2008), and hence zooplankton advection into and out of the fjord (Arnkvaern et al. 2005). We therefore assume we sampled a single population of Parasagitta elegans persisting yearround, an assumption supported by oceanographic data from the 2008 to 2009 mooring (C. Griffiths pers. comm.).

\section{Physical environmental and primary production}

Temperature, salinity and in situ fluorescence were measured continuously by a mooring placed in close vicinity to our sampling station ( $<0.5$ nautical miles). The depth of the seabed and mooring was $191 \mathrm{~m}$. Four Seabird CTDs measured conductivity, temperature, pressure and density every $12 \mathrm{~min}$ at 19, 30, 90 and $180 \mathrm{~m}$. In addition, Vemco temperature miniloggers measured temperature every $20 \mathrm{~min}$ at 46, 56, $76,111,126$ and $151 \mathrm{~m}$. A SeaPoint fluorometer and a light sensor measured fluorescence and photosynthetically active radiation (PAR; 400 to $700 \mathrm{~nm}$ ) every $12 \mathrm{~min}$ at $29 \mathrm{~m}$ depth. Only approximate PAR and chlorophyll a (chl a) data were available from the light sensor and the fluorometer due to the absence of suitable light fluorescence and water samples for calibration during much of the year. The raw PAR and fluorescence data were normalized between 0 and 1 to identify the approximate timing of the phytoplankton bloom. Samples for quantitative chl a values were collected at lower resolution, monthly from February to June 2009. The fluorescence data 
corresponded well with the quantitative chl a data, with values $>1 \mu \mathrm{g} \mathrm{chl} \mathrm{a} \mathrm{l}^{-1}$ not obtained before June.

\section{Zooplankton sampling}

Depth-resolved mesozooplankton samples were collected once or twice a month from July 2008 to August 2009 (Table S1 in the Supplement at www. int-res.com/articles/suppl/m499p077_supp.pdf). Three different nets were used to collect zooplankton throughout the study period: (1) WP3 (1 m² opening and $1 \mathrm{~mm}$ mesh size), (2) WP2 (0.25 $\mathrm{m}^{2}$ opening and $0.2 \mathrm{~mm}$ mesh size) and (3) MPS (Hydro-Bios multiplankton sampler; $0.25 \mathrm{~m}^{2}$ opening and $0.2 \mathrm{~mm}$ mesh size). The WP3 was used on the majority of sampling dates, except on dates during the summers of 2008 and 2009, when we used a small boat and thus were unable to sample with this larger net and only with the smaller, more portable WP2. In winter when sampling from sea ice, we were able to sample with both the WP3 and WP2 nets. The heavy MPS was used only from larger research vessels equipped with a crane (Table S1). Sampled depth intervals were standardized to 20-0, 50-20, 100-50 and 180-100 m (MPS and WP2) and 50-0, 100-50 and 180-100 m (WP3). The nets did not sample the $10 \mathrm{~m}$ immediately above the seabed (hyperbenthic zone).

Mesozooplankton samples were fixed in $4 \%$ buffered formalin-sea water solution immediately after sampling. Chaetognaths were sorted to the species level. Two species were present: the abundant Parasagitta elegans and the rarer Eukrohnia hamata. Lengths of all $P$. elegans were measured to the nearest $0.5 \mathrm{~mm}$ from the head to the tip of the tail, excluding the caudal fin.

\section{Net sampling efficiency and Parasagitta elegans abundance}

Since the MPS and WP2 gears had identical opening areas and mesh size, we combined length data collected by these 2 types of gear and compared the sampling efficiency of a 'combined' MPS+WP2 type of gear with that of the WP3. The 2 lengthfrequency distributions differed markedly (Fig. 1). The WP3 was most efficient at capturing individuals above $20 \mathrm{~mm}$, whereas the MPS+WP2 collected the whole Parasagitta elegans size range (2 to $44 \mathrm{~mm}$ ), but the smaller individuals more efficiently than the WP3 (Fig. 1). Since the MPS+WP2 collected the whole size range (Fig. 1) and samples from these

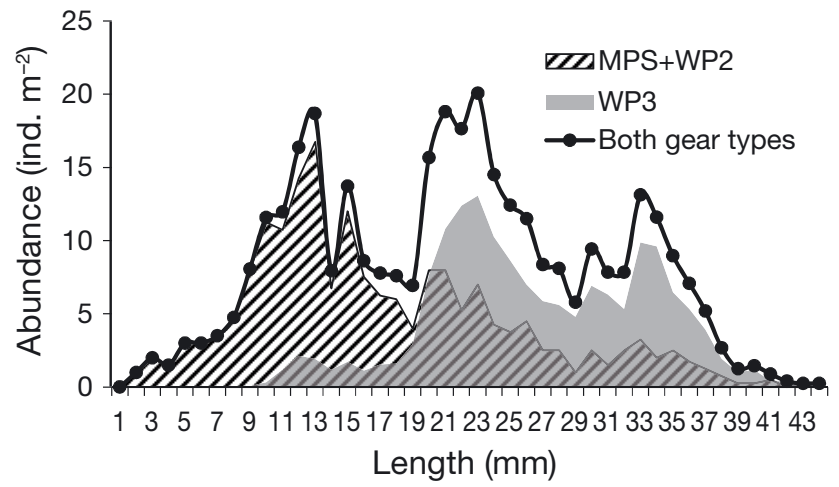

Fig. 1. Parasagitta elegans. Length-frequency distributions of $P$. elegans collected by each gear type. Striped area: MPS+WP2 gear $\left(0.25 \mathrm{~m}^{2}\right.$ opening area, $0.2 \mathrm{~mm}$ mesh size); grey area: WP3 (1 $\mathrm{m}^{2}$ opening area, $1 \mathrm{~mm}$ mesh size). Sampling efficiency was standardized to ind. $\mathrm{m}^{-2}$ calculated for the whole water column per sampling date for each gear (i.e. averages of 16 dates for MPS/WP2 sampling and 15 dates for WP3 sampling). The distribution from both gears combined is shown as the black curve. All 4 strata in the water column were sampled on most dates (see Table S1 in the Supplement for the few exceptions). All $1 \mathrm{~mm}$ size classes from 2 to $44 \mathrm{~mm}$ were represented in our samples

nets were available throughout the year, we used the MPS+WP2 data to investigate monthly trends in population and cohort abundances and vertical distributions. WP3 data were also included when identifying size cohorts in the population, determining growth rates and for maturity analyses, to increase sample size.

\section{Size cohort analyses}

Analyses of Parasagitta elegans size cohorts were performed using the finite mixture distributions (MIXdist) package in the statistical environment $\mathrm{R}^{\mathrm{TM}}$ (R Development Core Team 2008). This involved the identification of discrete size cohorts (peaks) in monthly pooled length-frequency data. Inspection of length distributions revealed the presence of 3 size cohorts (Fig. S1 in the Supplement), hereafter referred to as Cohorts 0,1 and 2. MIXdist then uses an automated optimisation process to estimate the average (mean) length and the standard deviation of each cohort. Mean lengths $( \pm \mathrm{SD})$ of the modelled distribution were used to estimate cohort length ranges in each month and these were used to allocate measured individuals into cohorts. The goodness-of-fit was verified by chi-squared statistics. In January, the mean lengths of all 3 cohorts, estimated by MIXdist, contrasted sharply with the December and February values $(20.7,21.7$ and $37.4 \mathrm{~mm}$ for Cohorts 0,1 and 2, 
respectively). Thus, in January, the values for Cohorts 0 and 2 were set to 13 and $33 \mathrm{~mm}$, to allow realistic growth estimates for all months. For the month of August, length data were available from both 2008 (WP3) and 2009 (MPS; Table S1 in the Supplement). When these August data were analysed for each year separately, the mean lengths of Cohorts 0 and 1 were found to differ by just 0.2 and $0.1 \mathrm{~mm}$, respectively, whereas the mean length of Cohort 2 was $2.2 \mathrm{~mm}$ longer in 2009 than in 2008. The August 2008 and 2009 data were pooled for the purposes of our analyses. The length-frequency data suggested reproduction from May to August. Mean cohort lengths in consecutive months were used to estimate monthly growth rates.

Due to our method of defining size cohorts in terms of monthly mean length ranges, some individuals caught could not be allocated to a cohort, and these correspond to the white area directly below the population curve (see Fig. 3). Note that on a few dates, samples were missing from at least 1 depth strata, so total water column abundances on these dates may have been higher than presented here (see Table S1).

\section{Maturity condition}

Chaetognaths are hermaphrodites. The male gonads (testes and seminal vesicles) produce and secrete the sperm, whilst the female gonads (ovaries and seminal receptacles) produce the ova and receive sperm from a sexual partner (Alvarino 1992). The seminal receptacles are known to develop in the later stages of the maturation cycle, shortly before reproduction (Russell 1932, Choe et al. 2003). To assess their state of maturity, Parasagitta elegans individuals from each month were stained with Borax Carmine solution, and the development of their ovaries and seminal receptacles, and the amount of sperm in their tails, were observed under a stereomicroscope. The same criteria have been used in several other studies to describe $P$. elegans maturity (e.g. Choe et al. 2003). Ovary length was measured to the nearest $0.1 \mathrm{~mm}$. The largest ovaries observed in this study were $\sim 24 \mathrm{~mm}$. Individuals showing advanced ovary development were taken as those with ovaries $\geq 5.4 \mathrm{~mm}$, while shorter ovaries $<5.4 \mathrm{~mm}$ were considered to be poorly developed. We assumed the threshold at this size because it was the maximum length of ovaries observed in Cohort 1 during the month of February, when members of this cohort first started to have well-developed seminal receptacles. Although no data on oocyte size or number were available during this study, other studies suggest that individuals can have many oocytes in their ovaries before they possess well-developed seminal receptacles (e.g. Russell 1932, Choe et al. 2003). Therefore, we assumed that ovaries are ripe at or above $5.4 \mathrm{~mm}$ length. This threshold also excluded all Cohort 0 individuals, which we assumed do not reproduce as they had no swollen seminal receptacles. Numbers of individuals with ovaries smaller and larger than $5.4 \mathrm{~mm}$ were recorded. Appearance of the seminal receptacles was described according to codes from 0 to 3 (our own approach): Code 0 indicated that no receptacles were visible, Code 3 indicated that receptacles were pronounced and protruding from both ovaries, and Codes 1 and 2 indicated intermediate levels of receptacle development. Numbers of individuals containing high quantities of sperm in the tail (i.e. sperm occupied at least $75 \%$ of the tail area) were also recorded.

\section{Vertical distributions}

To investigate the vertical distributions of Parasagitta elegans throughout the year, abundances in discrete layers of the water column (ind. $\mathrm{m}^{-3}$ ) were calculated for each sampling date and averaged for each month. Vertical distributions of the population and size cohorts were characterized by their weighted mean depths in the water column $\left(Z_{\mathrm{m}}\right)$, with standard deviations $\left(Z_{\mathrm{s}}\right)$, using the method of Manly (1977).

\section{RESULTS}

\section{Physical and biological environment}

Billefjorden was covered with land-fast sea ice from the end of December 2008 until the end of June 2009. During the ice-covered period, near-freezing temperatures $\left(-1.7^{\circ} \mathrm{C}\right)$ were observed throughout the whole water column (Fig. 2). In mid-June the sea ice was about to collapse, with many melt holes $(\sim 1 \mathrm{~m}$ in diameter). Chl a data from ice cores confirmed by visual observations of the underside of the sea ice revealed that the ice algal bloom peaked in early May. The phytoplankton bloom commenced approximately 1 mo later (Fig. 2). Temperatures up to $4^{\circ} \mathrm{C}$ were recorded in the upper $40 \mathrm{~m}$ in late summer and early autumn (Fig. 2). From $100 \mathrm{~m}$ depth to the bottom, cold waters (less than $-1.7^{\circ} \mathrm{C}$ ) persisted throughout the year (Fig. 2). 


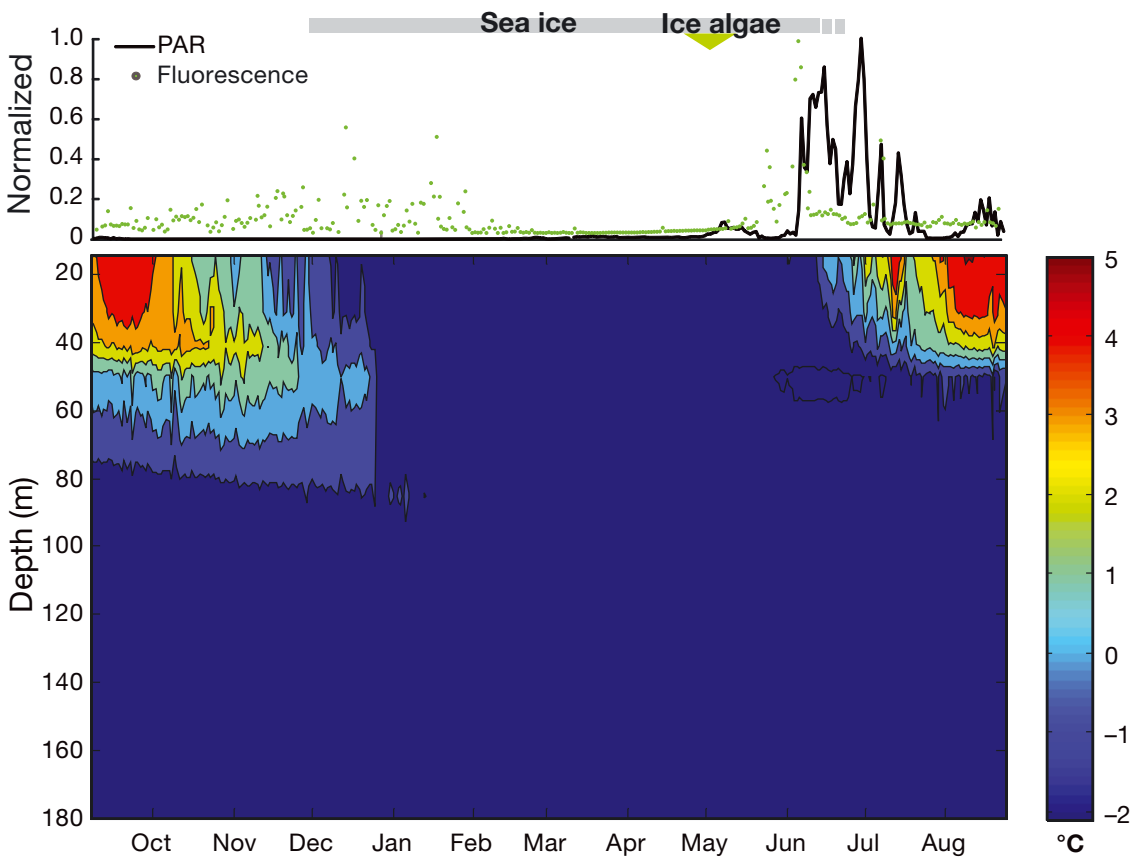

Fig. 2. Physical and biological environment in Billefjorden. Upper plot: annual variability in photosynthetically active radiation ( $\mathrm{PAR}_{i}$ unbroken line) and fluorescence (green dots), both measured at $29 \mathrm{~m}$ depth and normalized between 0 and 1 . The period of sea ice cover in the fjord is shown by the grey bar. PAR and fluorescence showed peak values in early June. The elevated fluorescence values observed in autumn, when no light is available, are due to digital noise, confirmed by water samples collected monthly with chl $a$ biomass close to zero $\left(<0.1 \mu \mathrm{g} \mathrm{chl} \mathrm{a} \mathrm{l}^{-1}\right)$. Lower plot: temperature $\left({ }^{\circ} \mathrm{C}\right)$ of the water column, calculated from mooring CTDs and miniloggers, situated at 19, $30,46,56,90,111,126$ and $180 \mathrm{~m}$.

Values are $7 \mathrm{~d}$ running averages

\section{Size cohorts, age structure and reproduction}

The Parasagitta elegans population size peaked towards the end of July (484 ind. $\mathrm{m}^{-2}$ ). Relatively high water column abundances $\left(\geq 344\right.$ ind. $\left.\mathrm{m}^{-2}\right)$ also

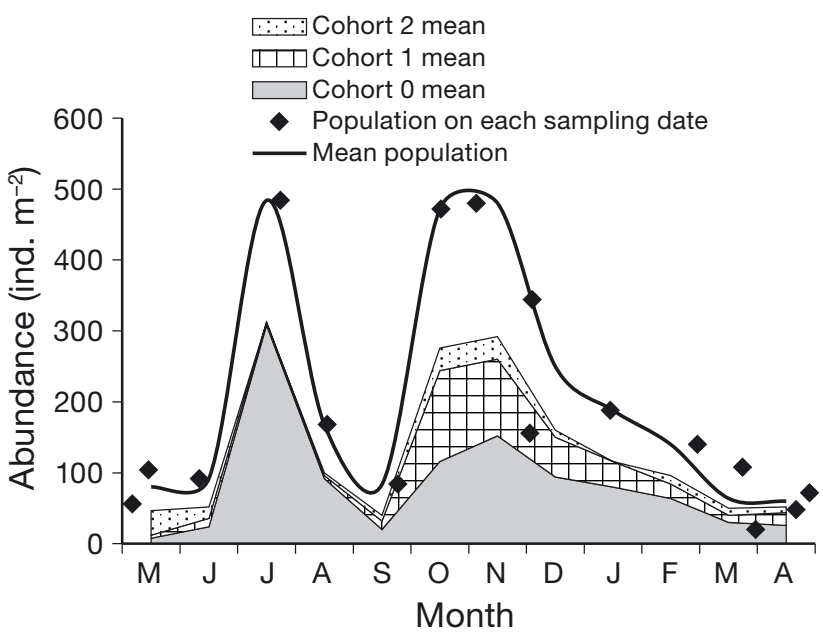

Fig. 3. Parasagitta elegans. Integrated abundances of the population on each sampling date (black diamonds) and averaged for each month (black curve), based on MPS+WP2 data only. Although the study did not start in May, this plotting decision was motivated by the finding that May was the start of the main birth season. For exact sampling dates, see Table S1 in the Supplement. Abundances of Cohorts 0, 1 and 2 averaged for each month of the year are shown as the grey area, the hatched area and the stippled area, respectively. In January and July, Cohort 2 was completely absent from the MPS+WP2 samples, but, in January, it was present in WP3 samples occurred in October, November and December. Population minimums ( $\leq 108$ ind. $\left.\mathrm{m}^{-2}\right)$ were realized in March, April, May, June and September (Fig. 3).

The main birth month was May, based on the numbers of $2 \mathrm{~mm}$ individuals present $\left(16\right.$ ind. $\mathrm{m}^{-2}$; Fig. S1 in the Supplement). Many more individuals $\leq 5 \mathrm{~mm}$ were also captured between May and August (e.g. 52 ind. $\mathrm{m}^{-2}$ in July), suggesting that the spawning period extended throughout the summer. There was also some evidence for a winter reproductive episode, since a few smaller individuals $(\leq 5 \mathrm{~mm})$ were also found in December and January (4 to 16 ind. $\mathrm{m}^{-2}$ ), but they were in insignificant numbers compared to summer. Members of all 3 cohorts were apparently present in the population during all months (although no members of Cohort 2 were identified in July, when the estimated length range of this cohort was particularly narrow). The 3 cohorts were clearly seen in the months of May, August, September, October, November, December and February, but were less distinct in June, July, January, March and April (Fig. S1).

The mean length ranges of Cohorts 0,1 and 2 during the year were 1.9 to $14.3,13.0$ to 29.7 and 29.0 to $34.2 \mathrm{~mm}$, respectively (Table 1, Fig. 4). Based on the mean lengths of the respective cohorts, the individuals that hatched in May took 1 yr to become Cohort 1 and 2 yr to become Cohort 2 (Fig. 4). Cohort 2 individuals persisted in the population for the whole year, suggesting that some Parasagitta elegans in Billefjorden live for $3+\mathrm{yr}$. 
Table 1. Parasagitta elegans. Body length statistics of the 3 size cohorts during 2008 and 2009. Mean values were estimated in the MIXdist library in $\mathrm{R}^{\mathrm{TM}}$, along with standard deviations. The goodness-of-fit was verified by chi-squared statistics. See Fig. S1 in the Supplement for monthly length-frequency histograms and Fig. 4 for the continuous growth curve. Values are based on all length data available (WP3-, WP2- and MPS-collected). Monthly growth rates were calculated as the difference in cohort mean length between months. All distributions were normal. na: not applicable

\begin{tabular}{|c|c|c|c|c|c|c|c|c|c|c|}
\hline \multirow{2}{*}{ Month } & \multirow[t]{2}{*}{$\mathrm{n}$} & \multicolumn{2}{|c|}{$\longrightarrow$ Cohort $0 \longrightarrow$} & \multicolumn{2}{|c|}{- Cohort $1-$} & \multicolumn{2}{|c|}{- Cohort $2-$} & \multicolumn{3}{|c|}{ Goodness-of-fit } \\
\hline & & $\begin{array}{c}\text { Mean } \\
\text { length } \pm \text { SD } \\
(\mathrm{mm})\end{array}$ & $\begin{array}{l}\text { Mean monthly } \\
\text { growth rate } \\
\left(\mathrm{mm} \mathrm{mo}^{-1}\right)\end{array}$ & $\begin{array}{c}\text { Mean } \\
\text { length } \pm \text { SD } \\
(\mathrm{mm})\end{array}$ & $\begin{array}{l}\text { Mean monthly } \\
\text { growth rate } \\
\left(\mathrm{mm} \mathrm{mo}^{-1}\right)\end{array}$ & $\begin{array}{c}\text { Mean } \\
\text { length } \pm \text { SD } \\
(\mathrm{mm})\end{array}$ & $\begin{array}{l}\text { Mean monthly } \\
\text { growth rate } \\
\left(\mathrm{mm} \mathrm{mo}^{-1}\right)\end{array}$ & df & $\chi^{2}$ & $\mathrm{p}$ \\
\hline May & 126 & $1.9 \pm 0.8$ & 6.4 & $13.0 \pm 1.5$ & 9.4 & $30.0 \pm 3.7$ & 2.5 & 38 & 38.37 & 0.45 \\
\hline Jun & 23 & $8.3 \pm 4.7$ & 0.3 & $22.4 \pm 1.9$ & 0.5 & $31.8 \pm 3.5$ & 0.7 & 38 & 44.77 & 0.21 \\
\hline Jul & 121 & $8.6 \pm 2.8$ & 2.3 & $22.8 \pm 0.9$ & -0.9 & $32.4 \pm 0.1$ & -0.4 & 18 & 15.84 & 0.60 \\
\hline Aug & 255 & $11.0 \pm 3.4$ & 0.0 & $22.0 \pm 1.8$ & -1.0 & $32.0 \pm 2.9$ & 0.0 & 35 & 22.54 & 0.95 \\
\hline Sep & 481 & $11.0 \pm 1.3$ & 1.8 & $20.9 \pm 2.4$ & 1.2 & $32.0 \pm 3.1$ & 1.1 & 30 & 40.11 & 0.10 \\
\hline Oct & 401 & $12.8 \pm 2.2$ & -0.5 & $22.1 \pm 2.6$ & 0.4 & $33.2 \pm 2.8$ & 0.1 & 33 & 36.48 & 0.31 \\
\hline Nov & 504 & $12.3 \pm 2.0$ & 0.6 & $22.5 \pm 2.7$ & 0.3 & $33.3 \pm 3.1$ & -0.5 & 33 & 46.02 & 0.07 \\
\hline Dec & 678 & $12.9 \pm 2.9$ & 0.1 & $22.8 \pm 2.7$ & -1.2 & $32.8 \pm 3.7$ & 0.2 & 38 & 67.96 & 0.002 \\
\hline Jan & 110 & $13.0^{\mathrm{a}} \pm 3.8$ & 0.3 & $21.6 \pm 4.0$ & 1.4 & $33.0^{\mathrm{a}} \pm 5.2$ & 0.5 & 43 & 45.83 & 0.36 \\
\hline Feb & 146 & $13.3 \pm 3.3$ & -0.2 & $23.0 \pm 3.1$ & 3.8 & $33.5 \pm 3.5$ & -0.3 & 39 & 43.36 & 0.29 \\
\hline Mar & 82 & $13.1 \pm 2.2$ & 1.2 & $26.8 \pm 5.4$ & -1.7 & $33.2 \pm 2.7$ & 1.0 & 32 & 22.50 & 0.89 \\
\hline Apr & 237 & $14.3 \pm 4.2$ & -1.3 & $25.1 \pm 4.1$ & 4.1 & $34.2 \pm 2.6$ & na & 37 & 25.72 & 0.92 \\
\hline${ }^{\mathrm{a}}$ Valu & fixe & by user & & & & & & & & \\
\hline
\end{tabular}

\section{Cohort abundances}

Cohort 0 was the most abundant cohort (Fig. 3). It comprised most of the individuals during the population peak in July (308 ind. $\mathrm{m}^{-2}$, when it had a mean length of $8.6 \mathrm{~mm}$ ), and the secondary peak in November (152 ind. $\mathrm{m}^{-2}$, mean length $=12.3 \mathrm{~mm}$ ). From January to June, Cohort 0 formed relatively low abundances ( 8 to 80 ind. $\mathrm{m}^{-2}$ ). Abundances of Cohort 1 peaked from October to November (108 to 128 ind. $\mathrm{m}^{-2}$; Fig. 3). In comparison, Cohort 2 was generally rare, but dominated the population in May (34 ind. $\mathrm{m}^{-2}$ ) after developing from Cohort 1 (Fig. 3).

\section{Growth}

The estimated annual growth rates of Cohorts 0,1 and 2 were $11.1,16.2$ and $5.0 \mathrm{~mm} \mathrm{yr}^{-1}$, respectively, with half or more (depending on cohort) of this growth taking place between May and June (Table 1, Fig. 4). From August until May, growth of both Cohorts 0 and 2 remained low $(\sim 2 \mathrm{~mm})$. Considerable growth at other times of the year was suggested only for Cohort 1, which gained $6.6 \mathrm{~mm}$ from February to April (Table 1, Fig. 4).

\section{Maturity}

The mean $( \pm \mathrm{SD})$ ovary length of all individuals investigated in this study was $2.9 \pm 2.6 \mathrm{~mm}$, and the mean ovary lengths of Cohorts 0,1 and 2 were $0.5 \pm$ $0.4,1.9 \pm 1.1$ and $5.1 \pm 2.4 \mathrm{~mm}$, respectively. No Cohort 0 individuals showed advanced ovary development (i.e. had ovaries $\geq 5.4 \mathrm{~mm}$ ) (Table 2). Cohort 1 observations revealed that time of maturation differed for male versus female function, with male

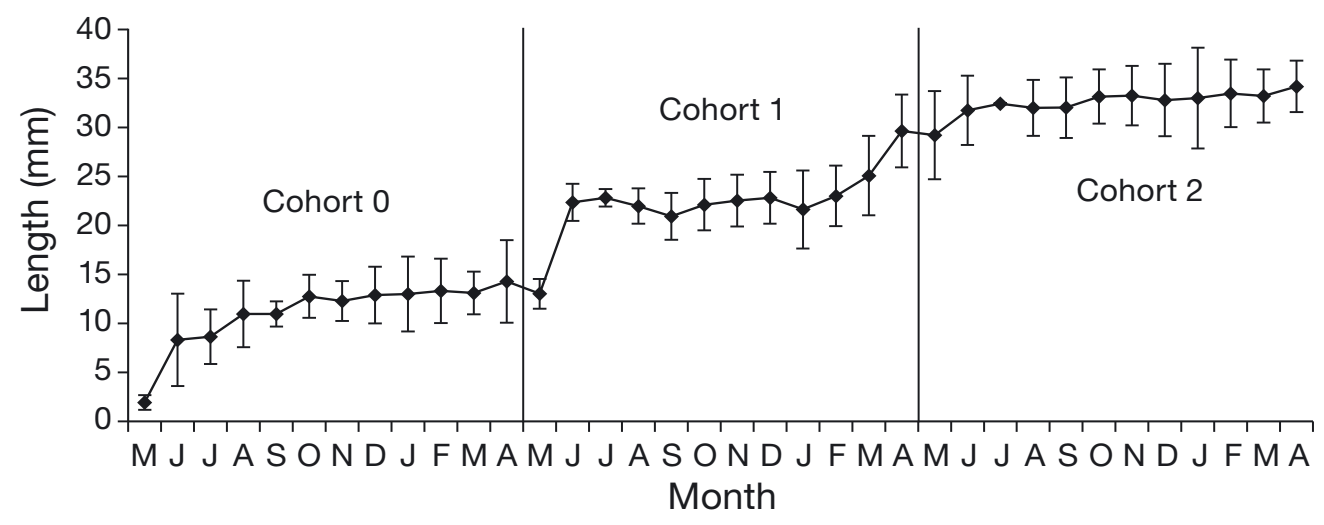

Fig. 4. Parasagitta elegans. Continuous growth curve (mean $\pm \mathrm{SD}$ ) for the Billefjorden population, produced from the mean lengths of the 3 size cohorts in adjacent months. Peak growth in all cohorts occurred between May and June 
Table 2. Parasagitta elegans. Percentages of individuals in each size cohort during 2008 and 2009 with advanced female (ovaries measuring $\geq 5.4 \mathrm{~mm}$ ) and male gonads ( $\geq 75 \%$ of the tail section containing sperm), and with pairs of pronounced seminal receptacles. See 'Materials and methods' for further details. Data in bold indicate cohorts in which 10 or more individuals were examined per month. $\mathrm{n}$ : number of individuals examined, nd: no data

\begin{tabular}{|c|c|c|c|c|c|c|}
\hline \multirow[t]{2}{*}{ Month } & \multirow{2}{*}{\multicolumn{2}{|c|}{$\begin{array}{c}\text { Ovaries } \geq 5.4 \mathrm{~mm} \\
\mathrm{n} \quad \% \text { present }\end{array}$}} & \multirow{2}{*}{\multicolumn{2}{|c|}{$\begin{array}{l}\text { Sperm load } \\
\text { n \% high }\end{array}$}} & \multicolumn{2}{|c|}{ Seminal receptacles } \\
\hline & & & & & $\mathrm{n}$ & \% present \\
\hline \multicolumn{7}{|c|}{ Cohort 0} \\
\hline May & 4 & 0 & 4 & 0 & 4 & 0 \\
\hline Jun & 4 & 0 & 6 & 0 & 4 & 0 \\
\hline Jul & 2 & 0 & 77 & $\mathbf{0}$ & 2 & 0 \\
\hline Aug & 4 & 0 & 27 & $\mathbf{0}$ & 4 & 0 \\
\hline Sep & 1 & 0 & 11 & $\mathbf{0}$ & 28 & $\mathbf{0}$ \\
\hline Oct & 39 & $\mathbf{0}$ & 40 & $\mathbf{0}$ & 40 & $\mathbf{0}$ \\
\hline Nov & 68 & $\mathbf{0}$ & 70 & $\mathbf{0}$ & 70 & $\mathbf{0}$ \\
\hline Dec & 91 & $\mathbf{0}$ & 93 & 0 & 80 & 0 \\
\hline Jan & 19 & 0 & 19 & 0 & 16 & $\mathbf{0}$ \\
\hline Feb & 31 & $\mathbf{0}$ & 27 & $\mathbf{0}$ & 20 & $\mathbf{0}$ \\
\hline Mar & 15 & $\mathbf{0}$ & 16 & $\mathbf{0}$ & 7 & 0 \\
\hline Apr & 15 & $\mathbf{0}$ & 17 & $\mathbf{0}$ & 12 & $\mathbf{0}$ \\
\hline \multicolumn{7}{|c|}{ Cohort 1} \\
\hline May & 6 & 0 & 6 & 0 & 5 & 0 \\
\hline Jun & 3 & 0 & 3 & 0 & 3 & 0 \\
\hline Jul & 1 & 0 & 1 & 0 & 1 & 0 \\
\hline Aug & 72 & $\mathbf{0}$ & 74 & $\mathbf{0}$ & 73 & $\mathbf{0}$ \\
\hline Sep & 180 & $\mathbf{0}$ & 190 & $\mathbf{0}$ & 40 & $\mathbf{0}$ \\
\hline Oct & 107 & $\mathbf{0}$ & 111 & 3.6 & 111 & $\mathbf{0}$ \\
\hline Nov & 166 & $\mathbf{0}$ & 174 & 23.6 & 144 & $\mathbf{0}$ \\
\hline Dec & 291 & $\mathbf{0}$ & 294 & 43.5 & 281 & $\mathbf{0}$ \\
\hline Jan & 52 & 0 & 52 & 57.7 & 47 & 0 \\
\hline Feb & 31 & 6.5 & 36 & 38.9 & 32 & 3.1 \\
\hline Mar & 31 & 22.6 & 33 & 48.5 & 29 & 13.8 \\
\hline Apr & 122 & 21.3 & 159 & 67.3 & 124 & 58.9 \\
\hline \multicolumn{7}{|c|}{ Cohort 2} \\
\hline May & 71 & 1.4 & 74 & 44.6 & 61 & 73.8 \\
\hline Jun & 4 & 0 & 4 & 50.0 & 4 & 0 \\
\hline Jul & 0 & ND & 0 & ND & 0 & ND \\
\hline Aug & 58 & 1.7 & 59 & 57.6 & 58 & 0 \\
\hline Sep & 137 & 2.9 & 140 & 62.9 & 58 & 50.0 \\
\hline Oct & 121 & 31.4 & 123 & 95.9 & 123 & 0 \\
\hline Nov & 98 & 64.3 & 104 & 94.2 & 83 & 7.2 \\
\hline Dec & 82 & 75.6 & 83 & 77.1 & 80 & 1.3 \\
\hline Jan & 13 & 61.5 & 13 & 92.3 & 13 & 38.5 \\
\hline Feb & 40 & 90.0 & 39 & 89.7 & 42 & 7.1 \\
\hline Mar & 14 & 100.0 & 15 & 73.3 & 10 & 90.0 \\
\hline Apr & 86 & 44.2 & 52 & 71.2 & 86 & 93.0 \\
\hline
\end{tabular}

gonads (observed in autumn; Table 2) preceding advanced ovaries (first observed in spring; Table 2). In both Cohorts 1 and 2, advanced ovaries peaked in spring, and, in Cohort 2, they were also observed in late autumn-winter (Table 2). Individuals started to show high volumes of sperm in their tails $(\geq 75 \%$ of the tail area), at approximately $1.5 \mathrm{yr}$ of age. In April, $\sim 70 \%$ of Cohort 1 individuals had reached these high amounts of sperm in their tails (Table 2). Similarly to advanced ovaries, high sperm loads were relatively common in Cohort 2 throughout the year. Pairs of well-developed seminal receptacles (i.e. Code 3) were present in members of both Cohorts 1 and 2, with high proportions (up to $93 \%$ ) of individuals in both cohorts possessing these in March, April and May. As with advanced ovaries, seminal receptacles were also frequently observed in members of Cohort 2 in late autumnwinter (Table 2).

\section{Vertical distribution and seasonal migration}

Parasagitta elegans occupied much of the water column (Figs. 5a \& 6). The peak primary production months, May, June and July (also the month of peak $P$. elegans abundance) were characterized by a shallower distribution of Cohort 0 than in other months of the year (Figs. 5b \& 6). A 2-sample t-test revealed that the average mean depth of Cohort 0 was shallower at this time (May to July) than in autumn (August to October; $\mathrm{df}=3, t=-3.44, \mathrm{p}=0.041$ ). However, the vertical distribution of Cohort 0 did not vary between the remaining adjacent 3 mo periods of the year. No differences in the vertical distributions of Cohorts 1 and 2 were observed between any 3 mo consecutive periods (2-sample $t$-tests, $\mathrm{p}>0.05)$. Cohort 1 (Fig. 5c) and Cohort 2 (Fig. 5d) seemed to show affinities for relatively deeper waters, and Cohort 2 was absent from the upper $50 \mathrm{~m}$ during $10 \mathrm{mo}$ of the year. The generally low abundances of Cohort 2 throughout the year may make some of the mean depth estimates for this cohort unreliable.

\section{DISCUSSION}

Based on our findings, the life history of Parasagitta elegans in Billefjorden can be summarized by the following key points: (1) the population comprises 3 size cohorts corresponding to age classes; hence, the potential lifespan is at least $3 \mathrm{yr}$ (2) Cohort 1 individuals develop male gonads prior to female gonads, while members of Cohort 2 possess 
advanced male and female gonads year-round; (3) the presence of mature female gonads in Cohorts 1 and 2 prior to the appearance of high numbers of small ( $\leq 5 \mathrm{~mm}$ ) newborns from May to July suggests spring and early summer to be the main spawning season; (4) length-growth in all 3 cohorts mainly occurs in summer and; (5) the vertical distribution of Cohort 0 was significantly shallower during the summer productive period than in autumn, whereas Cohorts 1 and 2 were typically distributed in deeper waters year-round.

\section{Lifespan and cohort dynamics}

Three cohorts and a potential lifespan of at least 3 yr agree well with reports from other locations around Spitsbergen and the Barents Sea (Falkenhaug 1993, Timofeev 1995), as well as the Kara Sea (Timofeev 1989). Parasagitta elegans populations residing at lower latitudes with warmer temperatures have considerably shorter lifespans, e.g. 3 mo at St. Margaret's Bay in the West Atlantic (33 to $44^{\circ} \mathrm{N}$; Samemoto 1971). Russell (1932) reported generation times and breeding cycles of a little over 1 mo in Ply- mouth, UK, although Russell may have sampled different populations during his $1 \mathrm{yr}$ study (Jakobsen 1971)

The 3 discrete size cohorts observed in our study also agree well with several other studies from Arctic and sub-Arctic areas (e.g. Dunbar 1962, Welch et al. 1996). Cohorts were relatively obvious in many months. During the less clear months, this seemed to be due to the absence of a clear Cohort 2 peak. Overall, Cohort 2 was the rarest of the size cohorts. However, the maximum size remained around $40 \mathrm{~mm}$ in all months, showing that the larger individuals were never completely absent (see the discussion below on their potential hyperbenthic distribution) and also pointing towards a lifespan $>3$ yr for some individuals. In June and July, the absence of this peak can be attributed to the lack of WP3 sampling. The WP3 net proved to be more efficient at capturing the larger individuals (Fig. 1). Cohort 1 grew much faster than Cohort 2 throughout the year, the latter most likely investing more energy in reproduction than in growth. In January, some Cohort 1 individuals had already attained the lengths of the smaller Cohort 2 individuals, causing an overlap in the distributions of Cohorts 1 and 2 .
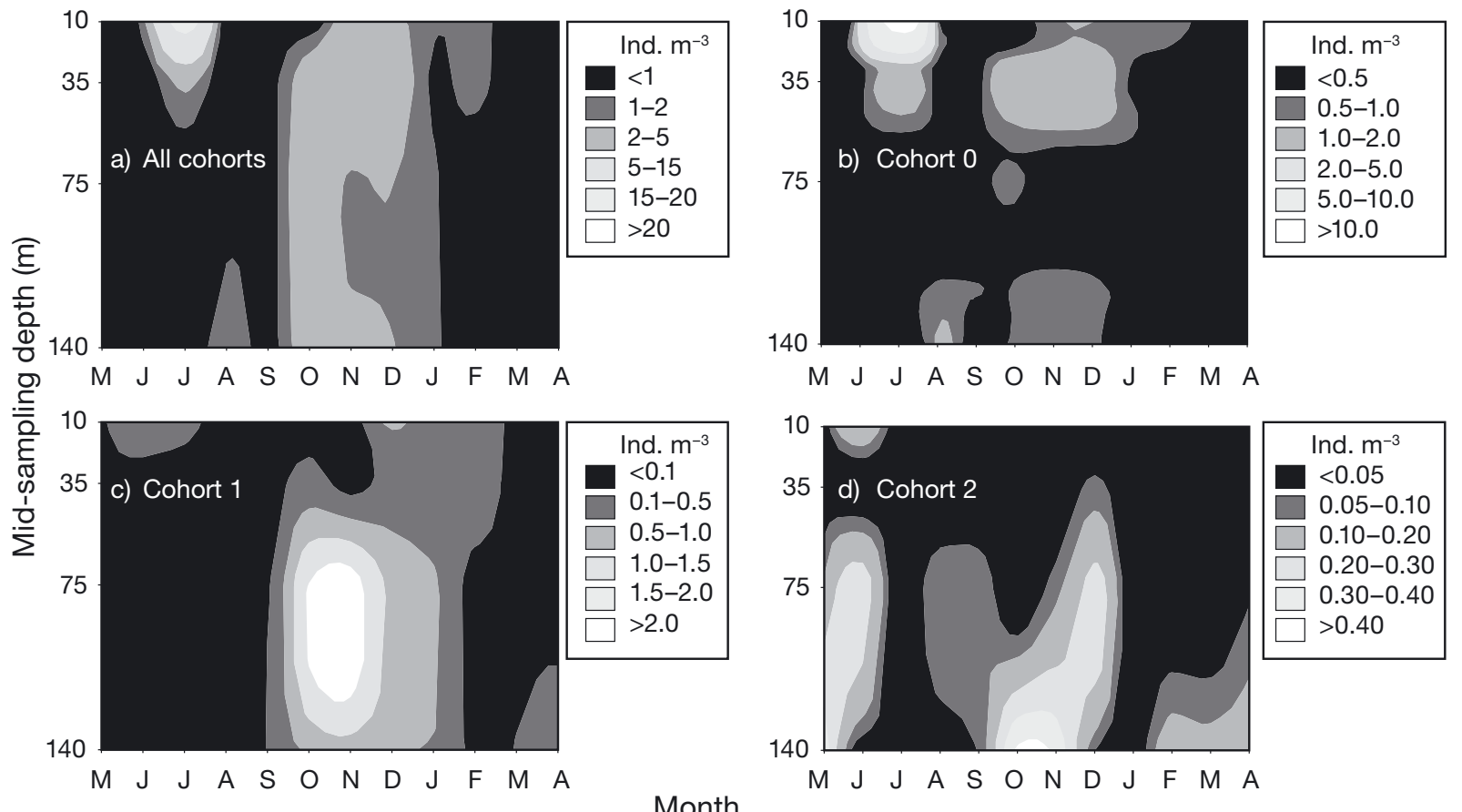

Fig. 5. Parasagitta elegans. Contour plots showing the seasonal vertical distributions of (a) the whole population and $(\mathrm{b}-\mathrm{d})$ the 3 size cohorts, based on MPS+WP2 data. Each sampled strata is represented on the $y$-axis by its mid-depth. For those months when data were collected on 2 sampling dates, the abundances shown are averages. Plots were produced in Minitab $16^{\mathrm{TM}}$ using the Distance interpolation method. Note the different scales for abundance in each plot and that Cohort 2 individuals were absent in the MPS+WP2 samples in January and July 


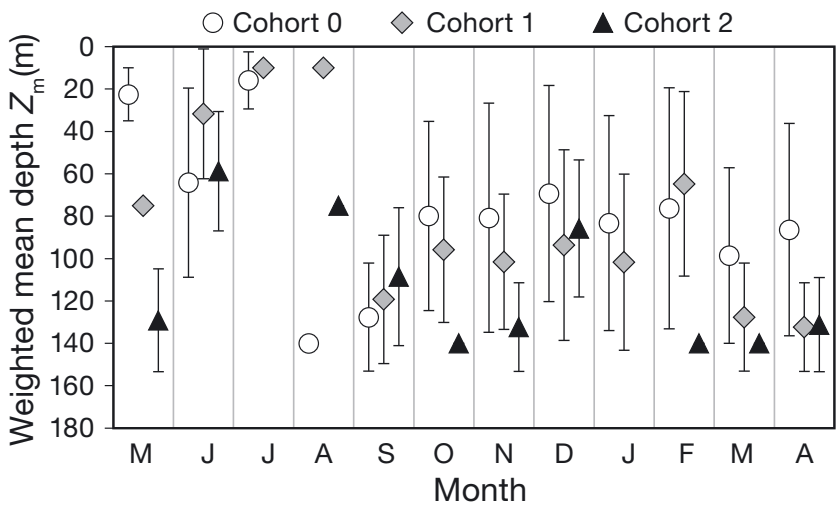

Fig. 6. Parasagitta elegans. Weighted mean depth of occurrence in the water column $\left(Z_{\mathrm{m}}\right)$ of Cohorts 0,1 and 2 throughout the year, plus standard deviation $\left(Z_{\mathrm{s}}\right)$ bars, based on MPS+WP2 data. As Cohort 2 was not present in the MPS+WP2 samples in January and July, no data are presented for Cohort 2 in these months. In some other cases, abundances were too low to allow standard deviations

\section{Spring-summer strategy: breeding, intense feeding and elevated growth rates}

The main period of reproduction for Parasagitta elegans in Billefjorden was spring and early summer. The mean length of Cohort 0 in May was very close to the reported length of newly hatched larvae $\left(\sim 1.2 \mathrm{~mm}_{i}\right.$ Kotori 1976), indicating that this is the start of the main spawning period. Individuals $<6 \mathrm{~mm}$ were captured in May, June, July and August, peaking in July, suggesting that the reproductive season is relatively long, at least compared to some estimates for this species in the North Pacific (e.g. Kotori 1999 and references therein) and North Atlantic Oceans (e.g. Conway \& Williams 1986, Tiselius \& Peterson 1986). Peak spring/summer breeding is common in P. elegans at high latitudes (e.g. Kramp 1939, Samemoto 1971), but a breeding season lasting from July into the winter was reported in sub-Arctic Hudson Bay (Dunbar 1962). In temperate regions, breeding seasons can typically be even longer (Terazaki 2004 and references therein). Higher temperatures and less pulsed food availability in the south, and thus the potential for continuous growth and development, are potential explanations for this latitudinal pattern. The vertical distribution of Cohort 0 was particularly shallow during the main reproductive and primary production period in the fjord (May, June and July). Although P. elegans var. arctica may reproduce at depth (e.g. Kramp 1939, Samemoto 1987), its buoyant eggs rise and typically hatch near the surface (Hagen 1999 and references therein). By emerging in relatively shallow waters in early summer, Cohort 0 individuals have access to a wide range of copepod prey, which graze and reproduce during the ice algal and phytoplankton blooms (Søreide et al. 2010). For these small chaetognaths, prey size is an important factor. Saito \& Kiørboe (2001) showed that $P$. elegans $<5 \mathrm{~mm}$ in the North Sea fed almost exclusively on prey $<350 \mu \mathrm{m}$ in length. In Billefjorden, the prey in this size range is represented by small cyclopoids such as Oithona similis, as well as Calanus nauplii and the young Calanus stages. The early stages of Calanus glacialis, $\mathrm{CI}$ and CII are also available prey sources, and these young developmental stages also peaked in the upper $50 \mathrm{~m}$ in June and July in Billefjorden (Bailey 2010).

Having already developed advanced ovaries and synthesized considerable amounts of sperm, members of Cohort 1 possessed well-developed seminal receptacles in March/April, suggesting that they will be able to reproduce in the next days to weeks. Once eggs are laid, they may hatch within $\sim 2 \mathrm{~d}$ (Brusca \& Brusca 1990). In Cohort 1, male gonads developed earlier than female gonads (sex-specific maturation), with ovaries reaching advanced stages several months after male gonads. This difference may lead to some individuals functioning first as males and then as both males and females (Alvarino 1992). This could be an adaptation to ensure cross-fertilisation, and may increase overall fecundity as female fecundity is likely to be more dependent on body size than the male component. Some authors have suggested that chaetognaths die after laying their first batch of eggs (e.g. Russell 1932, Alvarino 1992), but, in our study, the persistence of Cohort 2 throughout the year rather suggests that they may be iteroparous, reproducing several times before dying (also suggested by others: Conway \& Williams 1986 and references therein). Maturity data support this, showing that they may reproduce during both their second and third year. However, in Cohort 2, observations of advanced ovaries fell drastically in April, and from May to August few Cohort 2 individuals possessed advanced ovaries. This could possibly be due to ovary shrinkage after egg laying (Dallot 1968), although very few large specimens were collected in June and July, since we did not sample with the WP3 in these months. Observations of advanced ovaries in Cohort 2 increased again in autumn and peaked in this cohort in March. However, these observations were only indicative of iteroparity, and a semelparous strategy could also give rise to the same observations, given age-specific reproduction (as well as variability among individuals with respect to timing within the season). 


\section{Autumn-winter strategy: maturation, possible migrations and reduced growth rates}

There is evidence in our study that Cohort 0 individuals hatching in spring-summer migrate to deeper waters as they age, possibly to reduce their exposure to visually searching predators or to follow the depth distributions of their prey. Chaetognaths are tactile predators, using hair fans to sense prey vibrations in the water column (Saito \& Kiørboe 2001 and references therein). In autumn and winter, feeding opportunities for older chaetognaths may peak at depth. For instance, the calanoid copepods of the genus Calanus diapause at depth (Falk-Petersen et al. 2009). These copepods are very abundant in Billefjorden (Arnkvaern et al. 2005, Bailey 2010) and may be important prey for older chaetognaths.

Parasagitta elegans growth rates in autumn and winter generally fell below those in spring and summer, which could suggest reduced feeding rates and, furthermore, little direct impact of these arrow worms on the overwintering populations of copepods (in agreement with unpublished data from Grigor et al.). Cohort 2 had low growth rates throughout the year (total growth of $5 \mathrm{~mm}$ ), suggesting little growth after maturation, in agreement with results from Baffin Bay (Samemoto 1987) and Resolute (Welch et al. 1996). Cohort 1, however, grew considerably from around $23 \mathrm{~mm}$ in February to $30 \mathrm{~mm}$ in April. Whilst this strong growth could be an artefact of our method of detecting size cohorts from length-frequency data, Welch et al. (1996) similarly observed high winter growth rates for adolescents in the cold environment of Resolute (Canadian Arctic). Saito \& Kiørboe (2001) showed that individuals $>12.5 \mathrm{~mm}$ can feed on many prey size classes $>250 \mu \mathrm{m}$, suggesting that adolescents and adults are unlikely to face food shortages in winter. Calanus abundances dropped drastically from February to April (Bailey 2010), and predation from Cohort 1 could have played a role.

MPS data suggested that the Parasagitta elegans population had an apparent minimum in September (84 ind $\mathrm{m}^{-2}$ ) before reaching a second peak in November. However, the WP3 data did not reveal the same trough in September, showing mean abundances of 153 ind. $\mathrm{m}^{-2}$, which were more comparable with the August and October values. The large difference in abundances between the MPS and WP3 nets may be due to patchiness, which always poses a problem when sampling macrozooplankton, combined with the fact that the MPS data were obtained during the day, whereas the WP3 data were sampled at night. The MPS data suggest that Cohort 0 abun- dances increased $\sim 6$-fold from September to October, which may suggest some autumn production. However, the abundance of the other cohorts increased similarly to Cohort 0 , and no individuals $<6 \mathrm{~mm}$ were found in September or October, which points to no autumn reproduction. A few individuals $<6 \mathrm{~mm}$ occurred in December, January and February, suggesting some winter reproduction in Billefjorden. These could be the offspring of Cohort 2, which possessed advanced ovaries at this time, and a few members of Cohort 2 also possessed swollen seminal receptacles in autumn and winter. However, $<6 \mathrm{~mm}$ individuals comprised $<5 \%$ of the $P$. elegans population in these months, compared with up to $13 \%$ of those caught in summer months, and the proportion of $P$. elegans with mature gonads in winter was much lower than in spring (for ovaries) and early summer (for receptacles). The lack of mature individuals during the polar night agrees well with results from other Svalbard fjords in 2012 and 2013 (J. J. Grigor et al. unpubl. data).

Potential migration behaviours of larger chaetognaths in the lower part of the water column may also explain the second population peak in November. We did not sample the lower $10 \mathrm{~m}$ above the seabed during our study, the hyperbenthic zone where high abundances of large chaetognaths can occur (Choe \& Deibel 2000). In fact, image analysis of the hyperbenthic community in Kongsfjorden (Svalbard) in autumn 2012 showed high abundances of chaetognaths just above the sea floor (J. Laudien pers. comm.). ROV recordings made in Baffin Bay (Canadian Arctic) in August 2013 also showed high densities of large chaetognaths in the hyperbenthic zone (bottom depth was $\sim 370 \mathrm{~m}$ ). They hovered in position above the seabed until approached by the ROV and then quickly darted away (L. Fortier unpubl. data). Similarly Choe \& Deibel (2000) showed that $25 \%$ of the total Parasagitta elegans biomass in the water column occurred in the lowest $1 \mathrm{~m}$, and Mature Stage III comprised $46 \pm 26 \%$ of the chaetognaths here throughout the year. In our study, measured abundances of Cohorts 1 and 2 in October and November were much higher than in autumn, possibly because they migrated upward in the water column, and thus were more representatively sampled by our nets.

\section{Concluding remarks and outlook}

Our study shows the importance and potential of field campaigns with high temporal resolution within the annual cycle. As a result of this design, we ob- 
tained robust knowledge of the scheduling of the major events in the life cycle of Parasagitta elegans in the highly seasonal environments of the high Arctic. High-resolution seasonal sampling is important for proper parameterisation and development of lifehistory and annual routine models for this and similar species (Varpe et al. 2007). Such models are needed for an improved understanding and quantification of life-history trade-offs and for predictive powers in studies of environmental change (McNamara \& Houston 2008, Varpe 2012). Further studies of chaetognath reproductive strategies, including sex allocation and energy storage (Pond 2012) are particularly interesting avenues. We recommend a continued focus on abundant predatory zooplankton, especially on gelatinous plankton, which, due to their nonvisual food search, may be less restricted by seasonality at high latitudes than grazers and visual predators.

Acknowledgements. This work was carried out as part of the ConocoPhillip-funded project Arctic Sea in Winter Time (ArcWin) and the Cleopatra I and II projects (Project Nos. 178766/S30 and 216536) funded by the Norwegian Research Council. The authors thank the staff and students at the University Centre in Svalbard, particularly Jørgen Berge and Tove M. Gabrielsen, who supported us in our regular samplings, Lilith Kuckero for providing data on ice algae, and Allison Bailey for data on Calanus and valuable help in the field and laboratory. Thank you also to Colin Griffiths at the Scottish Association for Marine Science for handling the oceanographic mooring and successfully retrieving its data. The authors also thank 3 anonymous reviewers for their helpful feedback, and colleagues at Université Laval in Québec for constructive suggestions during the preparation of the manuscript.

\section{LITERATURE CITED}

Alvarino A (1992) 22. Chaetognatha. In: Adiyodi KG, Adiyodi RG (eds) Reproductive biology of invertebrates. V. Sexual differentiation and behaviour. John Wiley \& Sons, Chichester, p 425-470

Arnkvaern G, Daase M, Eiane K (2005) Dynamics of coexisting Calanus finmarchicus, Calanus glacialis and Calanus hyperboreus populations in a high-Arctic fjord. Polar Biol 28:528-538

Bailey A (2010) Lipids and diapause in Calanus spp. in a high-Arctic fjord: state-dependent strategies? Tracking lipids through the polar night. MSc thesis, University of Tromsø and University Centre in Svalbard

Brusca RC, Brusca GJ (1990) Invertebrates. Sinauer Associates, Sunderland

> Choe N, Deibel D (2000) Seasonal vertical distribution and population dynamics of the chaetognath Parasagitta elegans in the water column in the hyperbenthic zone of Conception Bay, Newfoundland. Mar Biol 137:847-856

Choe N, Deibel D, Thompson RJ, Lee SH, Bushell VK (2003) Seasonal variation in the biochemical composition of the chaetognath Parasagitta elegans from the hyperbenthic zone of Conception Bay, Newfoundland. Mar Ecol Prog Ser 251:191-200

Conway D, Williams R (1986) Seasonal population structure, vertical distribution, and migration of the chaetognath S. elegans in the Celtic Sea. Mar Biol 18:298-301

Daase M, Falk-Petersen S, Varpe $\varnothing$, Darnis G and others (2013) Timing of reproductive events in the marine copepod Calanus glacialis: a pan-Arctic perspective. Can J Fish Aquat Sci 70:871-884

> Dale K, Falk-Petersen S, Hop H, Fevolden SE (2006) Population dynamics and body composition of the Arctic hyperiid amphipod Themisto libellula in Svalbard fjords. Polar Biol 29:1063-1070

Dallot S (1968) Observations préliminaires sur la reproduction en élévage du chaetognathe planctonique Sagitta setosa Müller. Rapp P-V Reun Comm Int Explor Sci Mer Mediterr 19:521-523

Dunbar MJ (1962) The life cycle of Sagitta elegans in Arctic and subarctic seas, and the modifying effects of hydrographic differences in the environments. J Mar Res 20: 76-91

Falk-Petersen S, Mayzaud P, Kattner G, Sargent JR (2009) Lipids and life strategy of Arctic Calanus. Mar Biol Res 5: 18-39

Falkenhaug T (1993) Population structure and metabolism of Sagitta elegans var. arctica in the Barents Sea. In: Moreno I (ed) Proceedings of the 2nd international workshop of chaetognaths. Universitat de les Illes Balears, Palma, Mallorca, p 107-119

Feigenbaum DL, Maris RC (1984) Feeding in the Chaetognatha. Oceanogr Mar Biol Annu Rev 22:343-392

Ghirardelli E (1997) Chaetognaths. In: Guglielmo L, Ianora A (eds) Atlas of marine zooplankton: Straits of Magellan. Springer-Verlag, Berlin, p 245-275

> Hagen W (1999) Reproductive strategies and energetic adaptations of polar zooplankton. Invertebr Reprod Dev 36:25-34

Haney JF (1988) Diel patterns of zooplankton behaviour. Bull Mar Sci 49:583-603

> Hopcroft RR, Clarke C, Nelson RJ, Raskoff KA (2005) Zooplankton communities of the Arctic's Canada Basin: the contribution by smaller taxa. Polar Biol 28:198-206

Jakobsen T (1971) On the biology of Sagitta elegans Verrill and Sagitta setosa J. Muller in inner Oslofjord. Norw J Zool 19:201-225

Ji R, Jin M, Varpe Ø (2013) Sea ice phenology and timing of primary production pulses in the Arctic Ocean. Glob Chang Biol 19:734-741

Kosobokova KN, Hopcroft RR, Hirche HJ (2011) Patterns of zooplankton diversity through the depths of the Arctic's central basins. Mar Biodiversity 41:29-50

Kotori M (1976) The biology of Chaetognatha in the Bering Sea and the northern North Pacific Ocean, with emphasis on Sagitta elegans. Mem Fac Fish Hokkaido Univ 23: 95-183

Kotori M (1999) Life cycle and growth rate of the chaetognath Parasagitta elegans in the northern North Pacific Ocean. Plankton Biol Ecol 46:153-156

Kramp PL (1939) The Godthaab Expedition 1928. Chaetognatha. Medd Gronl 80:3-40

> Longhurst A (1985) The structure and evolution of plankton communities. Prog Oceanogr 15:1-35

> Manly B (1977) A further note on Kiritani and Nakasuji's model for stage frequency data including comments on the use of Tukey's jackknife technique for estimating 
variances. Res Popul Ecol (Kyoto) 18:177-186

McNamara JM, Houston AI (2008) Optimal annual routines: behaviour in the context of physiology and ecology. Philos Trans R Soc Lond B Biol Sci 363:301-319

Nilsen F, Cottier F, Skogseth R, Mattsson S (2008) Fjordshelf exchanges controlled by ice and brine production: the interannual variation of Atlantic water in Isfjorden, Svalbard. Cont Shelf Res 28:1838-1853

Pond D (2012) The physical properties of lipids and their role in controlling the distribution of zooplankton in the oceans. J Plankton Res 34:443-453

R Development Core Team (2008) R: a language and environment for statistical computing. R Foundation for Statistical Computing, Vienna

Russell FS (1932) On the biology of Sagitta. The breeding and growth of Sagitta elegans Verrill in the Plymouth area, 1930-1931. J Mar Biol Assoc UK 18:131-146

Saito H, Kiørboe T (2001) Feeding rates in the chaetognath Sagitta elegans: effects of prey size, prey swimming behaviour and small-scale turbulence. J Plankton Res 23: 1385-1398

Samemoto DD (1971) The distribution of herring (Clupea harengus L.) larvae along the southern coast of Nova Scotia with some observations on the ecology of herring larvae and the biomass of macrozooplankton on the Scotian shelf. Fish Res Board Can Tech Bull No. 252

Samemoto DD (1987) Vertical distribution and ecological significance of chaetognaths in the Arctic environment of Baffin Bay. Polar Biol 7:317-328

Søreide JE, Hop H, Falk-Petersen S, Gulliksen B, Hansen E (2003) Macrozooplankton communities and environmental variables in the Barents Sea marginal ice zone in late

Editorial responsibility: Anna Pasternak, Moscow, Russian Federation winter and spring. Mar Ecol Prog Ser 263:43-64

Søreide JE, Leu E, Berge J, Graeve M, Falk-Petersen S (2010) Timing of blooms, algal food quality and Calanus glacialis reproduction and growth in a changing Arctic. Glob Change Biol 16:3154-3163

Terazaki M (2004) Life history strategy of the chaetognath Sagitta elegans in the worlds' oceans. Coast Mar Sci 29: $1-12$

Timofeev SV (1989) Architechtonics of the Kara Sea pelagic zone (in Russian). In: Matishov GC (ed) Ecology and biological resources of the Kara Sea. KNC RAN, Apatity, p 86-93

Timofeev SV (1995) Parasagitta elegans Verrill (chaetognaths) in waters of Spitsbergen archipelago. Oceanology (Mosc) 34:788-791

Tiselius PT, Peterson WT (1986) Life history and population dynamics of the chaetognath Sagitta elegans in central Long Island Sound. J Plankton Res 8:183-195

Varpe $\varnothing ~(2012)$ Fitness and phenology: annual routines and zooplankton adaptations to seasonal cycles. J Plankton Res 34:267-276

Varpe Ø, Jørgensen C, Tarling GA, Fiksen Ø (2007) Early is better: seasonal egg fitness and timing of reproduction in a zooplankton life-history model. Oikos 116:1331-1342

Welch HE, Bergmann MA, Siferd TD, Martin KA and others (1992) Energy flow through the marine ecosystem of the Lancaster Sound region, Arctic Canada. Arctic 45: 343-357

Welch HE, Siferd TD, Bruecker P (1996) Population densities, growth, and respiration of the chaetognath Parasagitta elegans in the Canadian high Arctic. Can J Fish Aquat Sci 53:520-527

Submitted: December 28, 2012; Accepted: November 30, 2013 Proofs received from author(s): February 12, 2014 